\title{
MIDWEST NUCLEAR SCIENCE AND ENGINEERING CONSORTIUM
}

US Department of Energy Office of Nuclear Energy, Science and Technology

Award No / Contract No. DE-FG07-031D14531

Final Report

Grant Period: 10/1/2003 - 9/30/2010
Consortium Director and University of Missouri-Columbia
Principal Investigator:
Dr. Wynn Volkert
Volkertw@health.missouri.edu
Phone: 573-882-6759
Missouri University of Science and Technology
(formerly University of Missouri-Rolla)
Principal Investigator:
Dr. Arvind Kumar
Kumar@umr.edu
Phone: 573-341-4720

University of Missouri-Kansas City Principal Investigator:

Dr. Bryan Becker

BeckerB@umkc.edu

Phone: 816-235-1255

Linn State Technical College

Advanced Technology Center Principal Investigator:

Victoria A. Schwinke

Vicki.Schwinke@linnstate.edu

Phone: 573-897-5195

Polytechnic University of Puerto Rico Principal Investigator:

Dr. Angel Gonzalez

AGonzalez@pupr.edu

Phone: 787-751-7581

Kansas State University Principal Investigator:

Dr. Douglas McGregor

McGregor@ksu.edu

Phone: 785-532-5284

Original Collaborating Industry Partner:

AmerenUE Callaway Nuclear Plant

Mr. Christopher C. Graham

CCGraham@cal.ameren.com

Phone: 573-676-8380 


\section{MIDWEST NUCLEAR SCIENCE AND ENGINEERING CONSORTIUM INIE Final Report (10/1/2003 - 09/30/2010) \\ US Department of Energy Office of Nuclear Energy, Science and Technology Award No / Contract No. DE-FG07-031D14531}

\section{Executive Summary}

The objective of the Midwest Nuclear Science and Engineering Consortium (MNSEC) is to enhance the scope, quality and integration of educational and research capabilities of nuclear sciences and engineering (NS/E) programs at partner schools in support of the U.S. nuclear industry (including DOE laboratories). With INIE support, MNSEC had a productive seven years and made impressive progress in achieving these goals. Since the past three years have been no-cost-extension periods, limited -- but notable -- progress has been made in FY10. Existing programs continue to be strengthened and broadened at Consortium partner institutions. The enthusiasm generated by the academic, state, federal, and industrial communities for the MNSEC activities is reflected in the significant leveraging that has occurred for our programs.

The INIE funds revitalized NS/E fields as campus priorities by MNSEC partner institution administrations to enhance and stabilized NS/E programs in response to nuclear industry needs. Institutional investments included additional space, infrastructure and new permanent faculty lines. MNSEC institutions operate three research/training reactors (MURR, UMRR and KNRF) that are outstanding resources to support NS/E research and educational programs. Utilization enhancements at the reactors under INIE funding included programs for: innovative education/training, underrepresented student research, infrastructural improvements to accommodate an increased user base, new NS/E faculty hires, and increased external partner research collaborations (including DOE laboratories). 


\section{Table of Contents}

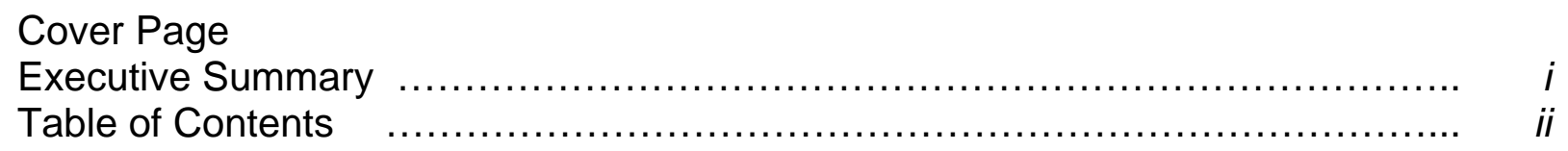
A. Final Report

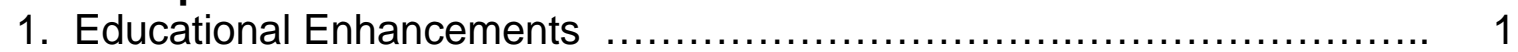

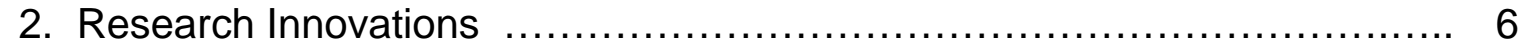

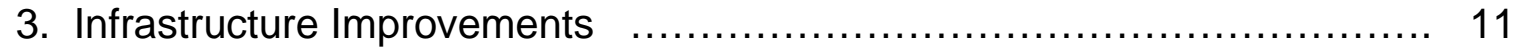
4. Big 12 Engineering Consortium's Nuclear Program $\ldots \ldots \ldots \ldots \ldots \ldots \ldots \ldots . \ldots \ldots$

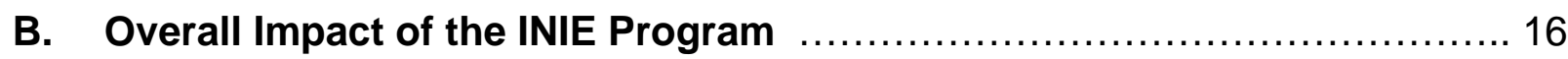




\section{Final Report (October 1, 2003 - September 30, 2010) Midwest Nuclear Science and Engineering Consortium (MNSEC)}

\section{A. FINAL TECHNICAL REPORT}

Year 7 was the third no-cost-extension year in which no additional funds were provided by DOE. Using the remaining grant funds, notable progress was made in the MNSEC, particularly considering the limited funds that were available. Since the level of progress made was relatively low in comparison to previous years, this section of the report contains specific areas of progress made this past year. Thus, the Cumulative Accomplishments for Year 7 are reported herein and can be combined with the more extensive Years 5 and 6 MNSEC Progress reports (i.e., Midwest Nuclear Science and Engineering Consortium Years 4- 6 INIE Progress Reports, Award No. DE-FG07031D14531, as submitted to DOE).

\section{A.1. Educational Enhancements}

MU: Advances in new and upgraded course offerings that were, in part, facilitated by INIE funding at MU and via the MU/UMKC collaborative educational program, developed in the past two years, are now routinely offered. These courses are provided on the MU campus, and in many cases via the internet. For example, the Nuclear Safeguards Science and Technology course is a cornerstone course in the recentlyapproved MU Graduate Certificate in Nuclear Safeguards Science and Technology. This "first-of-its-kind" Certificate program was jointly developed via a collaborative effort between MU faculty and Brookhaven National Laboratory scientists, and will be extended for availability to practicing professionals in industry, government labs and other organizations. Another example is the "Fulfilling Madame Curie's Dream" course that was developed using INIE funding to encourage enrollments of lower division undergraduate science and engineering students in nuclear-related degree programs. The course was developed as a collaborative effort between the MU College of Education School for Information Science and Learning Technology and the MU Nuclear Science and Engineering Institute (NSEI). This is a course designed for webbased delivery for dissemination across the U.S., and is one of the key courses that comprises the Big-12 NE Consortium educational program. These and other new NS/E courses provide important opportunities for MNSEC, Big-12 and US science and engineering students in NS/E areas to enable them to contribute to the future workforce that will serve the U.S. nuclear sectors.

For two-year technical educational initiatives for the nuclear industry, MU has partnered extensively with MNSEC partner, Linn State Technical College, in developing nuclear educational materials that are being adopted by additional two-year schools across the country that are partnering with a nuclear utility employer. These initiatives are discussed in more detail below in the LSTC section, and include collaborations with 10 
other schools across the United States working with nuclear employer partners. MU's collaboration in creating new curricular materials for nuclear technical education incorporates state-of-the-art knowledge and research on teaching and learning, activities for which MU has received significant national attention. Presentations have been made to national educational conferences throughout the INIE grant period of support, with a summary for the past year listed in Section B of this report.

The MU NS/E programs partially supported by INIE funds in combination with MU/MURR funding, were offered for undergraduate research trainees in the Summers of 2004 through 2009. In addition, the "Nuclear Science and Engineering for Secondary School Science Teachers" course was offered over the life of the INIE grant and will continue to be offered in the future (pending available funding), in which an average of 25 high school science teachers participated each year. The outcome this one-week, on-campus, three-credit hour course is the submission by each teacher of a teaching module on nuclear science appropriate for use in their home school classroom (in the fields of biology, physics, chemistry, or math). Teaching units such as these are an excellent means of increasing STEM information directly into secondary classrooms, as well as help encourage students into continued nuclear education and/or careers. Teachers who participate in this summer course are eligible to borrow MURR's portable Geiger counter kits for use in demonstrating nuclear concepts in their home school classrooms. Thus, INIE support has had a major impact on secondary level nuclear education, which contributes to high school teachers knowledgeable with nuclear science concepts to more effectively teach atomic and nuclear content to their science and math students. This teaching infrastructure supports a sustaining pipeline for nuclear science and engineering between secondary and post-secondary education.

UMKC: The INIE award has been particularly important in stimulating collaborative educational interactions that allow course sharing with the University of MissouriColumbia. The following Power Engineering courses have been offered at UMKC, including three NE courses taught via the internet:

- The Science and Technology of Homeland Security (INIE internet course)

- Energy Systems and Resources (INIE internet course)

- Nonproliferation of Weapons of Mass Destruction (INIE internet course)

- Power Plant Design

- Electromechanical Energy Conversion

- Environmental Compliance, Auditing and Permitting

- Power Generation Systems

- Contracts and Law for Engineers

The INIE Consortium structure allows for UMKC students to gain exposure to nuclear science and engineering, which is an experience that UMKC does not otherwise provide for their students.

MST: The Missouri University for Science and Technology has one of the largest nuclear engineering programs in the nation, with an undergraduate enrollment of over 
150 undergraduate and 15 graduate students. The substantial increase in NE enrollment and the INIE grant have had a positive effect on the NE program in obtaining an additional $3000 \mathrm{sq} f \mathrm{ft}$. of quality laboratory and office space from MST. Our growth in enrollment and the INIE grant has also helped in obtaining new tenure-track faculty positions in NE, bringing the total number of full-time tenure track faculty to five (with one part-time faculty person). In addition, the NE operating budget from MST General Operating Funds has more than doubled. None of these gains or MST's support to our program would have materialized without the INIE grant.

MST also recently became a member of the Southeast Universities Nuclear Reactors Institute for Science and Education (SUNRISE), to support the advancement of nuclear education in the Southeastern region of the US.

As a result of the recent ABET site visit, MST's Nuclear Engineering accreditation has been extended through 2014.

KSU: There has been a sustained increase in enrollment of both undergraduate and graduate enrollment in the MNE with a "nuclear option" program over the past few years. In 2002, the total enrollment in the nuclear option was only 19, which has now increased in 2010 to levels above 60 . Further, in 2002, there were only 2 graduate students in the nuclear program. Supported by only three nuclear engineering professors, the MS and PhD graduate enrollment has risen to $>20$. The Radiation Detection Instructional Laboratory (RDIL) was renovated entirely with new equipment and upgrades to this laboratory, partially supported by INIE, which played an important role. Enrollment in the nuclear measurements class (NE 612) had risen from only 4 in Fall 2002 to over 20 in Fall 2009, and further increases are anticipated. Funds from the INIE facilitated the enhancement of the program to increase student enrollment and programmatic quality.

PUPR: PUPR and MU collaborated to develop NS/E courses and research opportunities for Hispanic engineering students at PUPR. Courses in Radiation Safety, Radiation Detection and Nuclear Methods in Bioenvironmental Studies have been shared with PUPR undergraduate engineering students. A significant number of students with various BS Engineering degrees from PUPR have participated in summer undergraduate research experiences at MU/MURR over the life of the INIE grant, many of whom have enrolled in NS/E graduate programs at MU and other U.S. Universities. Several of the early students participating in the collaborative program have now graduated and taken jobs in nuclear industry and regulatory agencies.

\section{LSTC:}

In response to nuclear industry workforce infrastructural needs, LSTC expanded their original Nuclear Technology degree to include three new options, in addition to the existing Radiation Protection Technician degree. The new options -- graduates of which will contribute to the nuclear industry's workforce infrastructure needs -- are: Instrumentation and Controls; Reactor Operations, and Nuclear Quality Control. As a result of the approval of these new options by the Missouri Coordinating Board for 
Higher Education for initial offerings in the Fall 2008 semester, 63 new students enrolled in August 2008, and 55 new students enrolled in the Fall 2009 semester. With high demand for the NT programs, LSTC limited enrollments in Fall 2010 to 80 students. To support student recruitment, Linn State has successfully competed for national Nuclear Regulatory Commission Trade School Scholarship funding for the 2008-09 (\$150K), 2009-2010 (\$135K), and 2010-2011 $(\$ 150,000)$ academic years.

A significant national contribution is being made by the educational partnership of $\mathrm{MU}$ and LSTC with other two-year technical and community colleges across the United States, the nuclear industry, and government agencies sponsoring our various aspects of our initiatives. This partnership, facilitated initially by INIE support to Linn State in Years $1-4$ that allowed them to hire their original nuclear technology instructor, was further supported by:

1. A subaward under the University of Missouri's $\$ 3.2 \mathrm{M}$ U.S Department of Labor High Growth Job Training Initiative (HGJTI) grant (HG-15355-06-60) for creating a web-delivered curriculum benchmarked against industry training standards for Radiation Protection Technicians; and

2. Two subawards uner the University of Missouri's curriculum development grants with the US Nuclear Regulatory Commission Education Grants program (totaling \$200K) for a new Quality Control/Quality Assurance curriculum and for a new math skills strengthening class.

Two-year schools participating as pilot schools with MU and LSTC included: Estrella Mountain Community College (working with the APS Palo Verde Nuclear Plant); Hill College (Luminant-TXU's Comanche Peak), Central Virginia Community College (AREVA); MiraCosta Community College (SCE's San Onofre Nuclear Generating Station). In 2008, four new schools were added to the partnership: Aiken Technical Community College and their HBCU partner, Denmark College (SRNL, SC Vogtle Plant, and SCE\&G's Summer Plant), Lakeshore Technical College (Dominion Kewaunee), Chattanooga State (TVA), and Lake Michigan Community College (Entergy's Palisades Plant). In 2009, Indian River State College (Florida Power and Light's St. Lucie and Point Beach Plants) joined the partnership, and Orangeburg-Calhoun Technical College joined in 2010 (Savannah River National Lab, and several NPP partners). Bartlett Nuclear (an industry manpower provider) has been a major contributor to our curriculum development initiative for RPTs, by providing paid salaries (totally over $\$ 620 \mathrm{~K}$ as of the end of the DOL RPT grant in 2009) for two-year students to work outages around the country as the basis of their required second year internship class. A map of schools that have adopted the RPT curriculum is shown in Figure 1.

Subsequent to the DOL grant, MU and LSTC collaborated in successful proposals to the US Nuclear Regulatory Commission for curriculum development: "Development of a Two-year Associates Degree in Quality Control in Support of the US Nuclear Industry" 


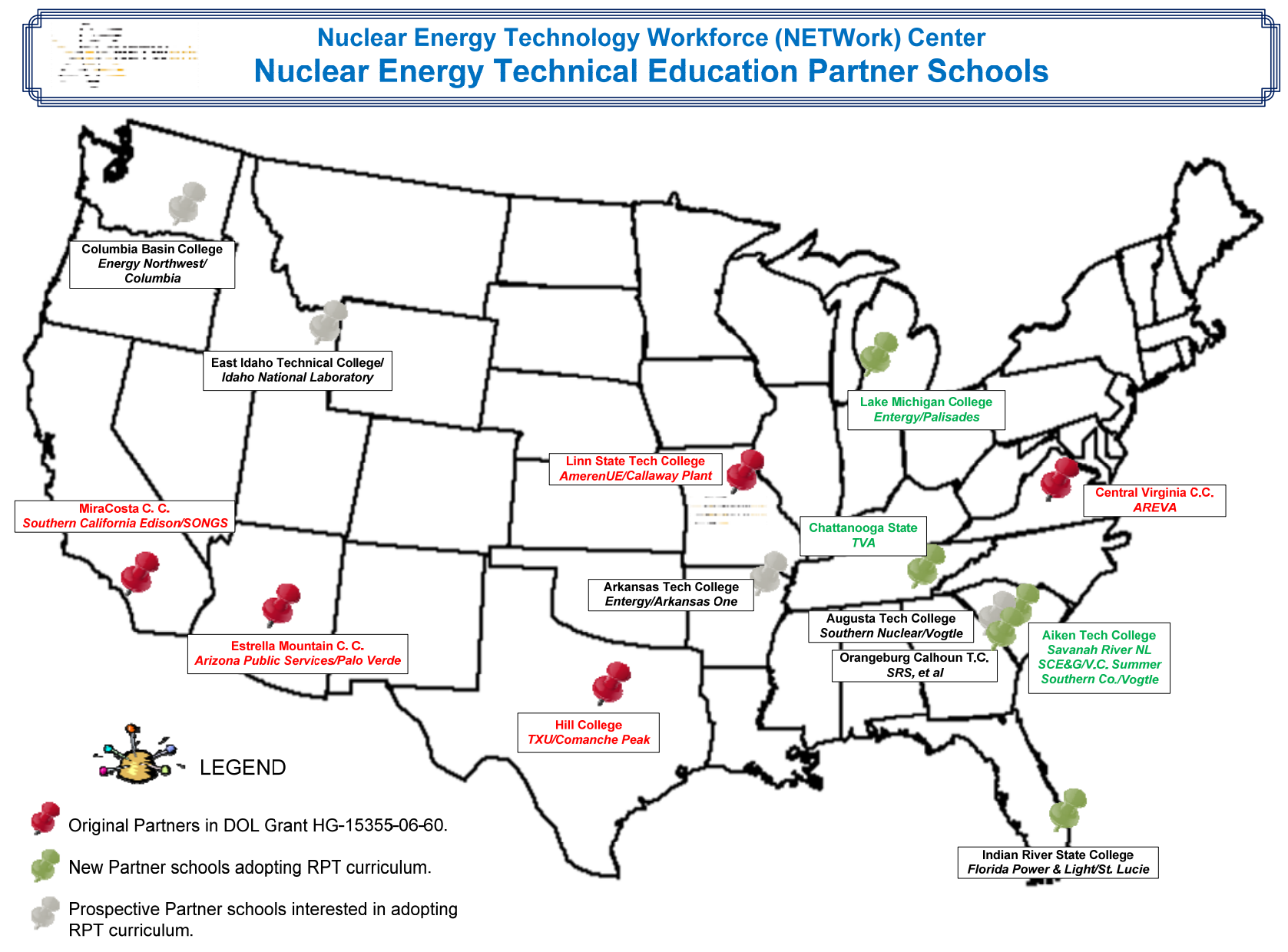

Figure 1: University of Missouri Partners in Nuclear Technical Education

(NRC-38-07-493) and "Development of a Problem-Based Nuclear Math Class as a Bridge Between Secondary and Higher Education in Support of the US Nuclear Power Industry" (NRC-38-070493-Amendment 001). The math course was being developed with input from area math teachers working with subject matter experts for implementation at the advanced high school student level, or for entering college freshmen (two-year or four-year). The goals of the "nuclear math" course were to allow students to become more comfortable in using math as a skill needed in jobs and/or continued education, and to encourage students to pursue careers in the nuclear industry. The course was constructed using nuclear industry training standards for math competencies of persons in various occupations at a nuclear power facility, and have been benchmarked against the Center for Energy Workforce Development's Energy Competency Model and against energy industry pre-employment exams with regard to required math skills.

As part of our ongoing collaborations in curriculum development to support manpower needs for nuclear technicians, MU and LSTC were active participants in the Nuclear Energy Institute's initiatives with the National Academy for Nuclear Training to develop a uniform curriculum guideline for two-year associate degree Radiation Protection 
programs (INPO/NANT ACAD 08-006, "Uniform Curriculum Guide for Nuclear Power Plant Technician, Maintenance, and Nonlicensed Operations Personnel Associate Degree Programs), and also for the uniform curriculum in Quality Control/Quality Assurance/ Nondestructive Testing (pending publication).

At the suggestion of Utilities Service Alliance (USA), Inc., (a nuclear utility support organization based in Kansas City metropolitan area, composed of nine single plant owners across the country), MU worked with LSTC to initiate a nuclear valve component installation/maintenance program taught by a nuclear valve vendor. The Summer 2010 experience at LSTC was very successful, with eight students completing the training, and future offerings of the program being planned at LSTC. MU is in discussions with the vendor and other schools in the NETWork program to disseminate the program for other geographic areas in the country to support local workforce needs.

In recognition of the successful partnerships that Linn State has developed for their educational programs for the nuclear industry, the national Workforce Management magazine awarded LSTC the 2008 Optimas Vision award. The award, presented to LSTC's President Donald Claycomb and Nuclear Technology instructor Bruce Meffert in October 2008 in New York, NY, was one of seven awards conferred annually by the WM magazine. Linn State's Nuclear Technology program was created as an industrydriven initiative between Ameren's Callaway Nuclear Plant, LSTC, and the University of Missouri.

MU-LSTC collaborations have resulted in significant national recognition for the high quality of our collaborative industry-driven curriculum initiatives, incorporating advances to learning and learning technology integration. Nuclear employers throughout the country refer to LSTC as the "gold standard" for nuclear technical education in the US. A chart illustrating the extent of collaborations that MU has had with LSTC and other partnering schools is given in Figure 2.

\section{A.2. Research Innovations}

MU: The MURR Utilization Grant Program and enhancements to neutron scattering research capabilities were an important component of the INIE grant.

\section{Neutron Scattering Research}

Neutron Scattering research advanced significantly at MURR during the life of the INIE award, primarily through the addition of two new Assistant Professors with expertise in this field. These hires were made possible by the INIE-supported upgrade of the TRIAX instrument at MURR and other enhancements to neutron scattering infrastructure. As an example, for one of these faculty hires, INIE funds were used to acquire an optical floating zone furnace for Dr. Owen Vajk's laboratory, a significant acquisition of research equipment that has allowed a new research program based on the ability to grow large single crystals of hexagonal manganite multiferroics. Multiferroics are 

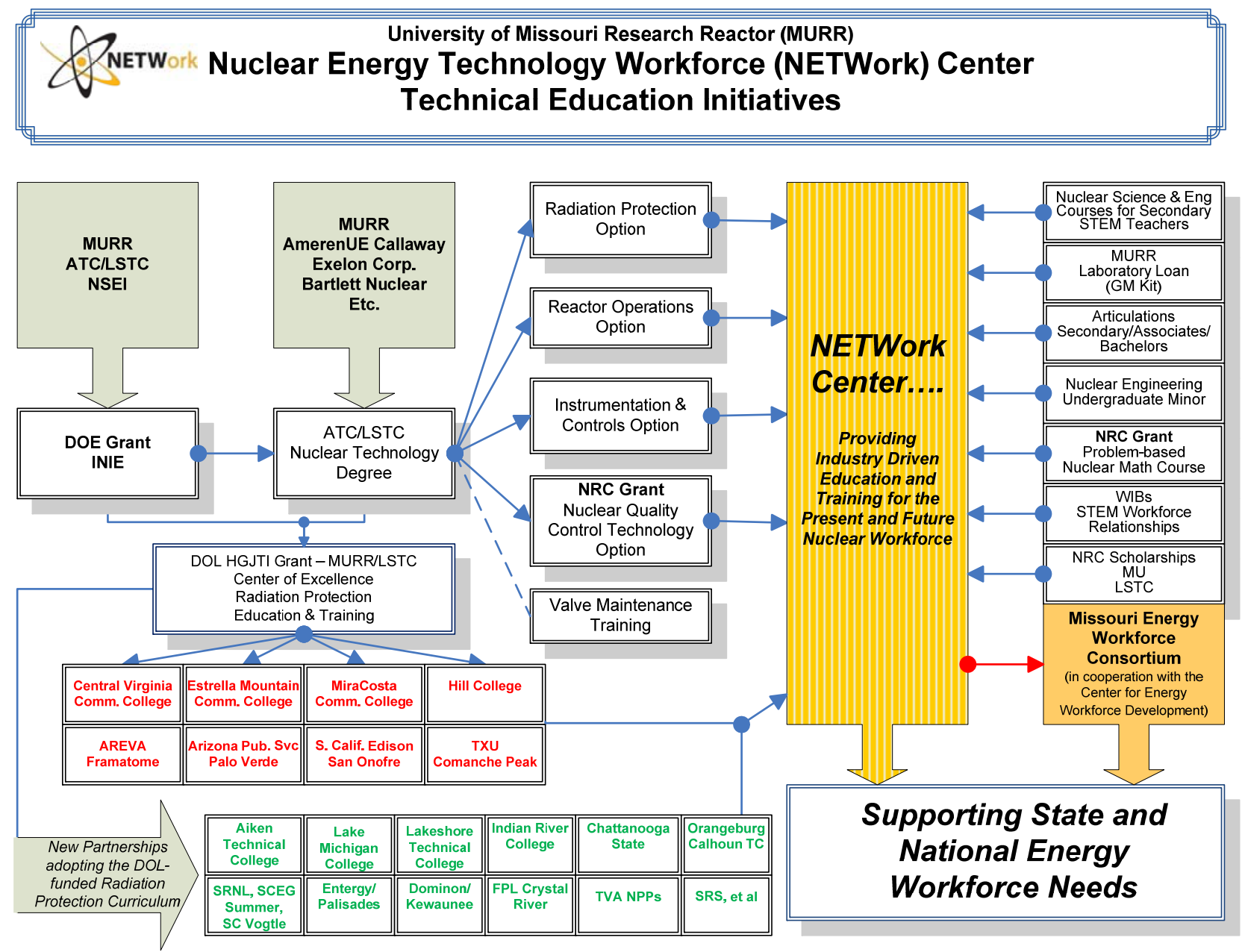

Figure 2: Collaborations Supported through MU's NETWork Partner Organizations

materials which exhibit simultaneous magnetic and ferroelectric order. This class of materials has attracted considerable attention because of possible technological applications arising from the interaction of these two types of order, and because of fundamental physics questions about how spin, charge and lattice degrees of freedom couple together. In order to create devices using the unique properties of multiferroics, a better understanding of the nature of magnetic-ferroelectric coupling in multiferroics is needed. Neutron scattering is an ideal tool for investigating such interactions, because it is sensitive to both lattice and magnetic structures, as well as excitations. Large single-crystal samples are needed to take full advantage of the capabilities of neutron scattering, and optical floating-zone crystal growth is the premier method for preparing high-quality samples of these multiferroic materials. The combination of crystal growth capabilities and neutron scattering facilities at MURR have allowed in-depth investigation of the hexagonal manganite family of multiferroics. 
Fundamental research conducted by MU faculty and students utilizing neutron scattering techniques has led to a host of technological advances in such diverse areas as drug design, the development of high-strength metals and cements, novel materials for electronic and magnetic devices, and hydrogen storage materials. Based on these achievements in science and engineering, recent progress in the design of neutron scattering instrumentation, and the potential for new discoveries, the United States has invested nearly \$2B in new facilities for neutron scattering over the past decade. Over the next five years, the number of operational neutron scattering beam lines available to the U.S. scientific community will increase by roughly $50 \%$ and many existing neutron spectrometers will be upgraded. This expansion provides exciting new opportunities for research in areas as diverse as bioscience, chemistry and chemical engineering, materials science and condensed matter physics, and mechanical engineering.

To maximize the scientific impact of these new capabilities in neutron scattering research, innovative methods of training the next generation of scientists and engineers are being organized. In response to this challenge, we have proposed a new paradigm for interdisciplinary training of Ph.D. students in full proposals in each of the last two years that we have been invited to submit based on pre-proposal submissions to the National Science Foundation's Integrative Graduate Education and Research Training (IGERT) Program. Our proposed IGERT research in neutron scattering encompasses three major interdisciplinary themes of condensed matter science: 1) biological macromolecules and biomaterials; 2) the structure and dynamics of strongly correlated electronic materials; and 3) design of artificial materials, including nanometric devices with novel functionalities. At the heart of our education plan is our university-based neutron source: the University of Missouri Research Reactor (MURR). Our proposal combines in-depth, hands on training at MURR with innovative theoretical courses encompassing the three major research themes.

As the highest power research reactor on a US university campus, MURR offers unique opportunities for training in neutron scattering techniques due to the larger amount of beam time available for this purpose compared to the national facilities. In addition, we propose to enhance research and training at MURR by research experiences at the world's most powerful neutron source, the Spallation Neutron Source at Oak Ridge National Laboratory (ORNL) and the presently expanding Center for Neutron Research at the National Institute of Standards and Technology (NIST). Our trainees will also learn to utilize state-of-the-art national facilities for materials synthesis and computer simulation at ORNL. These trainee experiences will be facilitated by the strong collaborative ties of many of the participating faculty in this project with scientists at our national neutron facilities.

MURR has recently invested over $\$ 7$ million in infrastructural upgrades toward its relicensing application (currently under review at the NRC) to ensure that this truly outstanding research facility is available for an additional 20 years. 


\section{MURR Utilization Grants Program:}

The INIE grant was used to create a seed-funding grant program designed to increase the utilization of MURR research capabilities. The new program accommodated MNSEC investigator and student use of MURR for new research projects, with over $\$ 240,000$ in INIE support allocated for the MURR Utilization Grant Program. A list of projects supported through the targeted MURR Utilization Grants Program funding follows in Table 1.

MST: The INIE grant, together with leveraged support, has been utilized to enhance research and educational capabilities of the MST Nuclear Engineering program. The cumulative effect of these efforts and investment is visible in the form of a number of valuable research infrastructure improvements:

- World class Two-phase Flow Thermal Hydraulics Laboratory which is equipped with a Photon ${ }^{\circledR}$ Fastcam Super 10KC camera, High Speed Digital Imaging System,

- Improvements in the Radiation Measurements Lab., including purchasing of a Intrinsic gamma detector system, an Alpha Spectroscopy system and a Thermo Electron Emerkit Survey Kit,

- A new Radiochemistry Laboratory added to the program,

- A state-of-the-art live two-way communication system (VBrick) between MST, LU, and MU.

These infrastructure improvements have allowed MST faculty to build research programs and increase NE student participation in undergraduate and graduate research initiatives.

KSU: Research on detector design and development in the SMART Laboratory at KSU is an important strength. This research includes the development of new semiconductors and scintillator materials for gamma ray spectrometers, new room temperature operated gamma ray spectrometer designs, compact high-efficiency neutron detectors, remote readout body dosimeters, and micro-pocket fission detectors for reactor controls.

Researchers in the SMART Laboratory have partnered with DOE Laboratories on various detector projects, which include Brookhaven National Laboratories (BNL), Oak Ridge National Laboratory (ORNL) and Sandia National Laboratory (SNL). In a partnership with BNL, room temperature operated high-resolution gamma ray spectrometers are being developed. The devices are simple to construct, referred to as "Frisch Ring" or "Frisch Collar" detectors, they are constructed from CdZnTe, and have shown energy resolution down to $0.8 \% \mathrm{FWHM}$ at $662 \mathrm{keV}$ at room temperature. In a partnership with ORNL and the University of Tennessee, high spatial resolution and high detection efficiency thermal neutron imaging arrays are being developed for installation in the Spallation Neutron Source. The devices are based on the perforated semiconductor technology developed in the SMART Laboratory at KSU. In a partnership with SNL, new scintillation materials for high resolution gamma ray detectors are being studied. The lanthanum halides offer promise as a significant replacement for $\mathrm{Nal}(\mathrm{Tl})$ detectors, and presently have resolution twice as good as 


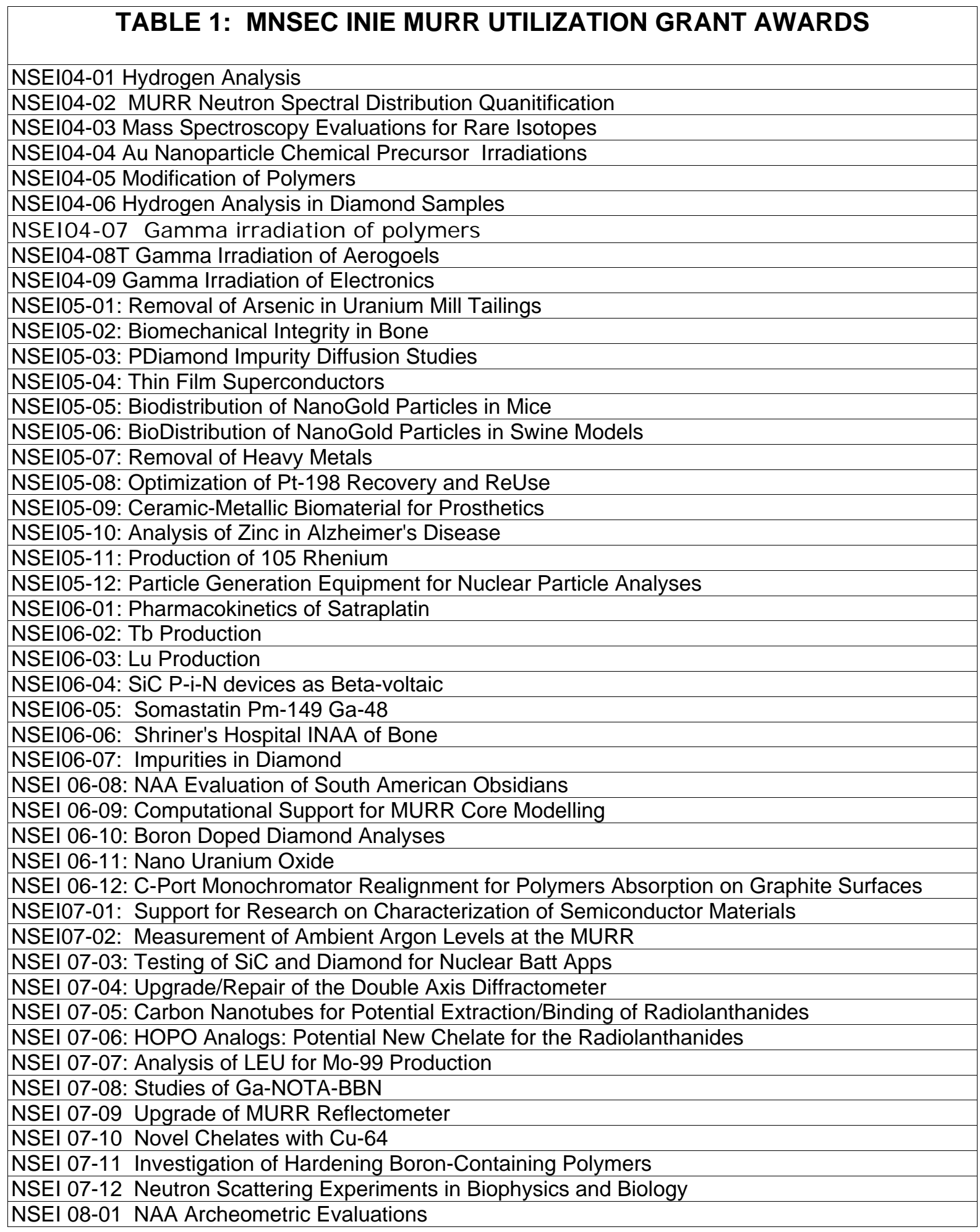


$\mathrm{Nal}(\mathrm{Tl})$. Methods to purify and grow the crystals, mainly $\mathrm{LaBr}_{3}$ variations, are being studied so as to decrease cost and improve crystal and performance uniformity. New methods to improve the hardness and reduced stress induced cracking are being studied with some success already.

PUPR: PUPR continues its collaboration with MU and other universities in the US in Nuclear Engineering research. The laboratory work associated with these research programs provides invaluable research skills and experiences that provide excellent background for the students, which supports their graduate nuclear education when they transfer to $\mathrm{MU}$ for the $\mathrm{PhD}$ degree.

LSTC: INIE support to MNSEC partners, MU and LSTC, have had a major impact on meeting workforce needs of the US nuclear industry by using the latest research and knowledge of learning and teaching strategies to create web-delivered, scenario-based curricula for dissemination to schools throughout the country that are partnering with nuclear employers.

\section{A.3. Infrastructure Improvements}

A listing of infrastructural improvements funded with INIE and other contributed funds is given in Table 2, with discussions of individual school initiatives following.

\section{MU:}

In addition to prior infrastructural enhancements to the MU Research Reactor's capabilities, the Automated Small Diameter Pneumatic Tube System design and implementation project was a major infrastructural enhancement project to design, fabricate, and test a new automated pneumatic sampling system for the MU Research Reactor. The new automated system -- which will allow higher throughout and faster analytic response for users of MURR facility's Neutron Activation Analysis capabilities -was a major engineering project conducted in two major phases. This phased approach was the least intensive approach to implementing the new system that provides for the maximum safety while we gain experience with the new system.

\section{Phase 1: Design, Fabrication, and Testing}

Fabrication has been completed on the major components of the small diameter $p$-tube systems for the MU Research Reactor. This activity includes design and fabrication of the feed system, the diverter gate, the counting station and the frame. The system was assembled and all the motor drives, solenoids, position sensors, and switches were wired to the controller, which was then linked to the programming computer and the radiation detection counting system.

The basic system and controls have been successfully tested for functionality.

Extensive testing of the system was conducted to ensure that samples can be selected from the sampler queue, irradiated for a specified preset time, counted for a specific preset time in the detector well, and then returned to the tray. Under normal conditions, 


\section{TABLE 2: SUMMARY OF MNSEC INFRASTRUCTURAL INVESTMENTS}

(All funding sources, DOE + leveraging and In-Kind) MSNEC Partner Institution

MU and MURR Infrastructure:

1. Distance Education System (VBrick)

2. MURR NAA Gamma Spectrometer System

3. MURR NAA Auto Sample Changing System

4. MURR Modular Radiation Detector

5. MURR NS TRIAX Upgrade

6. Laser Refurbishment/ Upgrade

7. FTIR Repair / Maintenance

8. NaI Well Detectors / Amplifiers

9. i-v, c-v Probing Station

10. Palas Nuclear Particle Generator

11. Nuclear Particle Data Acquisition System Upgrade

12. Liquid Scintillation System w/Alpha Capabilities

13. Postdoctoral Associates (2): Neutron Scattering, and Neutron Activation Analysis

14. MURR HP Technical Support

15. P.E. UV Vis Lambda Spectrometer

16. Nuclear Particle Counter

17. Raman Spectrometer Upgrade

18. Crystal Growth Furnace

19. Hall Measurement System

20. MURR Automated Pneumatic Tube System

21. MURR Beamport Upgrades for BNCT

22. MURR Lab /Office Bldg Addition (14,000 $\mathrm{ft}^{2}$ )

23. MURR Automated Pneumatic Tube System

24. MURR Ga Generator System

25. MURR Radiation Detection Instructional Lab UMKC Equipment:

1. Distance Education System (VBrick)

2. Computer Workstations

UMR and UMRR Equipment:

1. Distance Education System (VBrick)

2. Radiation Measurement Laboratory

3. New Faculty Development

4. Computer Workstations

5. Collier's Research

KSU Equipment:

1. Portable Multichannel Analyzer PUPR Equipment:

1. Radiation Detection Laboratory / Plasma Cooling

System

2. Plasma Data Acquisition System

3. New Material Fabrication / Characterization System LSTC/ATC Equipment and Other Enhancements:

1. Radiation Detection Lab

2. AASNT Director (hired 5/25/04)

3. AASNT Display Booth and Brochures

4. New Science Bldg Wing for AASNT Labs / Offices
Year 1
26,746
19,470

10,598

$\underline{\text { Year } 3}$

$\underline{\text { Year } 4}$

$\underline{\text { Years 5-7 }}$

40,200

32,945

12,465

19,850

80,000

16,083

11,350

6,575

23,132

16,711

7,276

8,000

54,000

85,000

89,095

83,948

29,256

59,993

62,478

14,118

75,495

5,000

185,000
22,000
165,000
$1,000,000$
$6,100,000$

165,000

34,098

80,000

7,500

8,125

3,560

$13,493 \quad 1,674 \quad 13,668$

24,000

33,670

44,500

20,000

8,597

8,000

14,192

1,195

10,625

$9,600 \quad 5,600$

$5,000 \quad 5,000$

34,000

47,000
53,975

239,279

53,975

53,975

50,000

8,535

200,000

$\mathbf{6 6 6 , 4 6 4} 7,688,292$ 
the failure rate of the vial in 100 samples was zero. In an extreme case, when the speed was increased by about $50 \%$ above normal, the failure rate was $3 \%$. In this case, the failure was not at the seal, but on the body of the vial itself. Therefore, it was concluded that the vial sealer was very satisfactory. In addition to testing the integrity of the vial, the mechanical reliability and repeatability of the sample transport system has been extensively tested. After calibration of the positioning system, over 1,000 test samples were run through the system, with no failures of the sample transport system observed - which is an important aspect of ultimate system performance. Data acquired from the PTube system detector is labeled and then stored on the data acquisition computer.

In Years 6 and 7, efforts were concentrated on finalizing the design and construction of the control system user interface to ensure that the system is user-friendly, and to ensure that in case of error or malfunction, the system can be recovered. Major accomplishments were made in this interface design and programming, which were completed in June 2010. As the system becomes fully functional (after Phase 2 is completed, as discussed below), future enhancements to the system functionality will be made to accommodate a wider range of user needs as feedback from users is received.

Phase 2: Integration of the PTube System into Routine MURR NAA Operations To integrate the new system into one of the beamports at MURR, a graphite terminal end for the PTube system was designed, specified, and ordered, with receipt of the graphite items in December 2010. Once the terminal has been installed on the beamport, MURR engineers will perform a full safety analysis on the system. We anticipate that users will have access to the finished PTube system in March 2011.

MST: As discussed elsewhere in this report, MST continues developing programs for increasing public awareness of and participation in nuclear science and engineering education through formal and informal interactions. MST has increased enrollment to over 150 undergraduate students and over 10 graduate students enrolled in the Nuclear Engineering department. MST's Research Reactor hosts facility tours and visits for over 1,000 persons annually, which increases the public's awareness of the role that nuclear science and technology plays in our world.

MST also continues to develop close relationships with HBCU institutions, Lincoln University and Tuskeegee University, in order to facilitate minority student participation in undergraduate and graduate education in Nuclear Engineering at MST. Implementation of a distance learning lab was fundamental to MST's ability to share coursework with LU to create this educational pathway, the goal of which is to increase minority participation in the nuclear industry workforce.

The MST Research Reactor implemented online control of the High Purity Ge Detection system. In addition, all pneumatic systems, sample changers, and safety locks have been password protected to increase security.

KSU: The new instrument upgrades for the Radiation Detection Instructional Laboratory (RDIL) were supported by the INIE program in 2007 and 2008. This 
includes development of four new student radiation detection work stations, all with new NIM bins and NIM components. RDTL is a crucial component of the NE612 Nuclear Measurements Course. The miniature multichannel analyzer was acquired with INIE funds and is an important asset for use in combination with nuclear measurements and reactor-based laboratory experiments.

PUPR: The INIE supported laboratory equipment acquisitions for a Radiation Detection laboratory have enhanced PUPR's overal research program in materials studies, primarily those of interest to NASA for deep space applications. The sharing of courses between MU and PUPR spurred resources being allocated at PUPR to create a stateof-the-art distance learning classroom, which is being used for receiving the shared nuclear engineering courses.

LSTC: As discussed in LSTC discussions in Sections A.1 and A.3, Linn State Technical College has added three new degree options to their original Nuclear Technology degree, creating long-term educational infrastructure for the US nuclear power industry, as well as nuclear medicine units, manufacturers that hire technicians for operations that involve nuclear processes, and national laboratories and other research organizations such as universities (e.g., the University of Missouri Research Reactor, which has hired five LSTC graduates as Reactor Operator Trainees, and one LSTC graduate as a Health Physics Technician). Augmenting the original Radiation Protection Technician option (initiated under funding from the MNSEC INIE grant), the three new options are: Reactor Operations, Instrumentation and Controls, and Nuclear Quality Control. In addition to direct manpower production at LSTC, the curriculum development activities in collaboration with MU have led to nine additional technical / community colleges in the US to start offering nuclear technical educational programs to support regional manpower needs. These schools, along with their nuclear industry employer partner, are listed in Section A.1 for MU.

\section{A.4. Big 12 Engineering Consortium's Nuclear Program}

The INIE grant provided funds in 2007, through both the MNSEC and the Southwest Consortium, to develop a Big-12 Nuclear Educational Initiative. As a result of this investment, a 3-year grant of more than $\$ 600,000$ from the U.S. Department of Education's Fund for the Improvement of Post-Secondary Education (KSU, lead organization) was awarded. Impressive progress has been made, including development of: 1) Consortium Memorandum of Agreement between Big-12 schools; 2) Memorandum of Agreement for the Big-12 Nuclear Engineering Consortium; and 3) Bylaws of the Big-12 Engineering Consortium. These documents are in App. 1 of MNSEC's Year 5 INIE report.

The Big 12 initiative is an important collaborative program in which the four Big-12 schools with nuclear engineering programs (KSU, MU, U.Texas-Austin and Texas A\&M) are collaborating to provide distance-learning courses to undergraduate engineering students at all Big-12 schools, particularly those eight that do not have NE programs on their campus. This program uniquely addresses an important national need to produce 
science and engineering undergraduate students with substantial backgrounds in the $\mathrm{NS} / \mathrm{E}$ areas that will be prepared to serve the expanding nuclear power workforce. The web site for this initiative is: www.big12engg.org 


\section{B. OVERALL IMPACT OF THE INIE PROGRAM}

The INIE impact on the MNSEC NS/E programs has been outstanding. Over the past seven years, the NS/E undergraduate and graduate student enrollment at all partner institutions has grown dramatically. It is important to note that the increased student enrollment has been sustained at the MNSEC partner institutions during the No-Cost Time Extension INIE grant period. The number of NS/E tenure track faculty members increased substantially since initiation of the MNSEC program, many of which were catalyzed by the INIE award. Infrastructural improvements at MNSEC Research Reactors -- facilitated by investments from the INIE award -- have had major influences on their ability to support NS/E research and educational programs and provided important long-term stability for the research reactor, themselves. Likewise, INIE facilitated the purchase or fabrication of new state-of-the-art instrumentation, as outlined in this report and previous reports (see previous MNSEC Progress Reports to DOE for complete list of instrumentation/infrastructure improvements) for NS/E Departments (including distance learning hardware and software). These infrastructure improvements have provided major enhancements for their respective research and/or training capabilities. All of these enhancements provide for the long-term viability of NS/E programs in MNSEC partner institutions that enables them to attract and effectively train increasing numbers of undergraduate and/or graduate NS/E students.

Undergraduate and Graduate Program Support, including the Big-12 Consortium:

The number of undergraduate NE majors at MST and KSU grew to over 150 and 60 at the start of 2009, respectively. Graduate programs at MU, MST and KSU also experienced very substantial increases in the number of NS/E, MS and PhD students. Development of effective NS/E programs for underrepresented minority students was emphasized with eight-week research/educational experiences at MU/MURR each summer for Hispanic and black undergraduate students, the joint educational collaboration between MST and Lincoln University (an HBCU) and the joint educational program between PUPR and MU. Development of the innovative Big 12 Consortium (KSU-lead institution) in Nuclear Engineering was a major achievement and may be used in the future as a model for expanding NS/E educational opportunities nationwide. These and other education enhancements demonstrate that the INIE award has been supremely successful in enhancing the quality and scope of educational programs in the MNSEC. Furthermore, growth in these educational programs has been based on investments from MNSEC partner institutions to ensure long-term sustainability and growth.

Infrastructural Enhancements for Research:

The NS/E research programs in the MNSEC experienced major advancements as a result of the INIE award. Excellent examples of investments made possible by INIE funds are:

- The Non-Destructive Analysis of Spent MOX Fuel and the High Intensity Radiation Measurements and Detection and Characterization research programs were enhanced in the MNSEC

- The Plasma Laboratory at PUPR 
- The SMART research programs at KSU,

- The new automated Small Diameter Pneumatic Tube Neutron Activation Analysis system at MURR, and

- Neutron Scattering, and Nuclear Aerosol research programs at MU

Clearly, these examples of achievements, among many others, that occurred over the past in the MNSEC NS/E research programs (as described in previous MNSEC Progress Reports to DOE) form a firm basis for continued future growth and excellence.

The MNSEC institutions and investigators have emphasized expansion of establishing partnerships with DOE laboratories, colleges, universities, and U.S. corporations (e.g., nuclear utilities). These efforts have achieved remarkable success as MNSEC investigators as a group have formed affiliations with all of the DOE laboratories, NIST, Nuclear Power plants, etc. The strength of these partnerships will continue to be an important factor in the expansion and quality of MNSEC NS/E programs in the future. The INIE award has played an essential and pivotal role in stimulating and facilitating new collaborative relationships with DOE laboratories and the nuclear industry.

\section{MU's Collaboration with Two Year Technical Schools:}

In response to nuclear industry workforce infrastructural needs, MU, LSTC, and other partnering schools made significant advances in accommodating new educational offerings to support employer demand across the country.

LSTC expanded their original Nuclear Technology degree to include three new options, in addition to the existing Radiation Protection Technician degree. The new options -graduates of which will contribute to the nuclear industry's workforce infrastructure needs -- are: Instrumentation and Controls; Reactor Operations, and Nuclear Quality Control. Development and implementation of the Nuclear Quality Control option was conducted collaboratively with MU, under funding from a 2008 US Nuclear Regulatory Commission Nuclear Education Grant.

As a result of the approval of these new options by the Missouri Coordinating Board for Higher Education for initial offerings in the Fall 2008 semester, 63 new students entered LSTC's two-year Nuclear Technology associate's degree program in August 2008, and 55 new students enrolled in August 2009. Enrollments were limited to 80 starting in 2010 , due to the exceptionally strong demand for studies in this program in relation to faculty available to teach the courses.

Also in collaboration with $\mathrm{MU}$ and under NRC grant support, work was initiated to develop a web-based, instructor led course to strengthen mathematics and problemsolving skills, with nuclear science and engineering problems as the learning context. This STEM enhancement course is being developed by area math teachers working with subject matter experts for implementation at the advanced high school student level, or for entering college freshmen (two-year or four-year). The goals of the "nuclear math" course are to allow students to become more comfortable in using math as a skill needed in jobs and/or continued education, and to encourage students to pursue 
careers in the nuclear industry. The course is being constructed using nuclear industry training standards for math competencies of persons in various occupations at a nuclear power facility. LSTC has been using the class for their entering class of 55 freshmen, and the course is ready for deployment to other 2-year schools and/or high schools as a means to strengthen math skills of their students.

LSTC and MU personnel participated in the Nuclear Energy Institute's nationwide Uniform Curriculum for technical education initiative for Radiation Protection Technicians, (INPO/NANT ACAD 08-006, "Uniform Curriculum Guide for Nuclear Power Plant Technician, Maintenance, and Nonlicensed Operations Personnel Associate Degree Programs). Linn State is one of the pilot program site schools that will benchmark LSTC RPT courses against the Uniform Curriculum guidelines. The web-based RPT curriculum has been benchmarked against these preliminary guidelines, the results of which have been conveyed to the other two-year schools that have adopted the RPT degree for their home institution. MU and LSTC have recently become involved with a similar initiative to draft a national uniform curriculum guideline for Quality Control / Quality Assurance / Nondestructive Testing technicians.

In recognition of the successful partnerships that Linn State has pursued for implementing educational programs for the nuclear industry, the national Workforce Management magazine awarded LSTC the 2008 Optimas Vision award. This prestigious award, presented to LSTC's President, Dr. Donald Claycomb, and Nuclear Technology instructor Bruce Meffert in October in New York, NY, is one of seven categories for which awards are conferred annually by the WM magazine. The citation for LSTC's award reads:

"In recognition of Linn State's prescience in meeting a critical industry need and creating lucrative opportunities for its students, the school wins the 2008 Optimas Award for Vision."

Linn State's Nuclear Technology program was created as an industry-driven initiative between Ameren's Callaway Nuclear Plant, LSTC, and the University of Missouri. INIE funding allowed LSTC to hire the school's original Nuclear Technology instructor. With the addition of the new options in the NT degree (as discussed above), LSTC now has three NT instructors, which provides organizational infrastructure at Linn State for responding to nuclear industry technical education needs.

A significant publicity effort was undertaken at the 2009 Conference on Nuclear Training and Education held in Jacksonville, Florida in February 2009. We hosted a booth in the exhibition area during the conference describing our curriculum development activities. A paper was presented (Miller, W.H., D.H. Jonassen, R.M. Marra, G.M. Neumeyer, R.L. Etter, M.A. Easter, M.M. Schmidt, H. Henry, I.G. Ionas, "The Role of Instructional Technologists in the Development of a Problem-Centered Radiation Protection Technician Curriculum," Proc of the Conf on Nuclear Training and Education CONTE09: An International Forum on Nuclear Training and Education and Workforce Issues Facing a Renewed Nuclear Energy Option, Jacksonville, FL, Feb 2009), and a panel discussion on academic/utility partnerships in support of workforce needs. A special workshop on the curriculum and lessons learned to date was included in the 
conference agenda ("Experiences in Problem-Based, Web-Delivered Curriculum Design for the Nuclear Industry: Demonstration of the US Department of Labor Funded Radiation Protection Technology Curriculum"), with about 40 conference participants attending. Topics discussed included: a background on RPT curriculum development effort and a demonstration of the problem-centered curriculum by Dr. William H. Miller; lessons learned in program implementation and hiring instructors by Miller and Christopher Graham, a Health Physicist from AmerenUE; the importance of industry/education collaboration by Mr. Graham; the significance of benchmarking curriculum to industry standards by Mr. Etter; and articulation of technical curriculum to four-year degrees by Dr. Gil Brown, University of Massachusetts - Lowell who is a member of the ABET Board of Directors.

In other activities to disseminate our educational materials, MURR hosted a booth at the 2009 Utilities Service Alliance Annual Summit (Nashville, TN). The booth registration fee $(\$ 1,000)$ was waived by USA/STARS. USA/STARS also supported a booth at the "Enhancing Our World through Nuclear Technology", combined U.S. WIN and WIN Global 2009 Conference, July 20-24, 2009, at the Grand Hyatt Washington in Washington, D.C. MU hosted a booth at the November 2009 ANS meeting (Washington, DC), and the November 2010 ANS meeting (Las Vegas, NV), at which information about nuclear education programs at partner schools was distributed.

Other publications regarding our curriculum development activities included:

- Robertson, J.D., R.L. Etter, W.H. Miller, G.M. Neumeyer, "Challenges and Opportunities In Nuclear Science and Radiochemistry Education at the University of Missouri," MARC VIII, Kona, Hawaii (April 5-9, 2009). This paper outlined activities at Linn State and the expansion of these activities through the DOL grant.

- Etter, R., W.H. Miller, G.M. Neumeyer, B.A. Meffert, T.J. Yeager, V.A. Schwinke, L. Kilfoil, "Development of a Problem-Based Undergraduate Nuclear Course to Strengthen Math Skills in Support of the U.S. Nuclear Workforce," Trans. Am. Nucl. Soc., 100, 70-72 (June 16, 2009).

- Goldin, E., W.H. Miller, R. Matthews, "Where O Where Have All the HP Techs Gone? And What're You Gonna Do About It?," Health Physics, 97(1), S65 (June 2009). This paper was given by Eric Goldin, who is the lead instructor of the RPT program at MiraCosta Community College.

- Miller, W.H., G.M. Neumeyer, and V.A. Schwinke, "Impact of Federal Grants Supporting Nuclear Technical Education Infrastructural Capacity," American Nuclear Society Annual Conference, November 7-11, 2010 (Las Vegas, NV).

In addition to paper presentations this past year, MURR hosted a booth at the Conference on Nuclear Technical Education (CONTE) in February 2009. We also offered a 2 hour workshop on the RPT curriculum and our experiences with its dissemination at the CONTE conference. MU will host a booth at the upcoming CONTE 2011 meeting. Meetings such as these provide high visibility venues to reach employer stakeholders with information on the RPT curriculum project to help stimulate student enrollments in our existing partner school degree programs, as well as to encourage these nuclear utility employers to consider 
collaborating with technical schools in their geographic area to adopt the curriculum to help meet their specific workforce needs in their region.

MU has worked to develop close relationships with the Missouri Department of Workforce Development to help recruitment of persons into the nuclear workforce, focusing on areas of the State of Missouri heavily impacted by the economic recession, especially automotive restructuring, to help attract workers with good technical and math skills into the nuclear workforce. The energy industry has been identified as a priority sector by the State of Missouri, which supports our initiatives in facilitating the creation of new organization, the Missouri Energy Workforce Consortium, in partnership with the national Center for Energy Workforce Development. Presentations on our initiatives were made in June 2009 on our nuclear technical education activities to the Missouri Workforce Investment Board Directors meeting in Jefferson City, MO, and in August 2009 at the Governor's Economic Development Conference in St. Louis, MO.

These relationships have expanded the range of MU's capabilities, resulting in the submission of proposals to various agencies for additional curriculum development for other technical occupations, the goal of which will be to centrally develop coursework benchmarked against industry training needs, that can be disseminated to other twoyear degree schools across the country who are partnering with nuclear employers in their geographic area to build a well-trained workforce for site-specific hiring needs. 